\title{
The Moderating Effect of Working Memory on the Relationship between Inattention and Aggressive Behavior in Attention-Deficit/Hyperactivity Disorder
}

\author{
Mi Young Jeong', Yeon Jung Lee ${ }^{2}$, Jung $\mathrm{Ho} \mathrm{Kim}^{3}$, and Seo Young Park \\ ${ }^{1}$ Michuhol-gu Community Mental Health Welfare Center, Incheon, Korea \\ ${ }^{2}$ Department of Psychiatry, Seoul Hospital, College of Medicine, Soonchunhyang University, Seoul, Korea \\ ${ }^{3}$ Department of Nursing, Masan University, Changwon, Korea \\ ${ }^{4}$ Department of Medical Sciences, Graduate School of Soonchunhyang University, Asan, Korea
}

\begin{abstract}
Objectives: Although aggressive behavior in children and adolescents with attention-deficit/hyperactivity disorder (ADHD) has previously shown correlations with hyperactivity/impulsivity, few studies have examined its association with inattention or the effect of working memory on aggressive behavior. This study aimed to assess the relationship between inattention and aggressive behavior and the effect of working memory on the relationship between inattention and aggressive behavior in children and adolescents with ADHD.

Methods: Thirty-one children and 26 adolescents with ADHD were retrospectively investigated. The subjects completed the Korean Wechsler Intelligence Scale for Children-Fourth Edition (K-WISC-IV), the Korean Child Behavior Checklist (K-CBCL), and the Korean Children's Depression Inventory (CDI).

Results: Inattention was positively correlated with aggressive behavior in children and adolescents with ADHD and working memory showed an insignificant correlation. However, working memory had a significant moderating effect on aggressive behavior by interacting with inattention. The moderating effect of working memory manifested when the working memory index score on the K-WISC-IV was 73.5 points or higher, and it had a significant effect on aggressive behavior.

Conclusion: This study shows that the severity of inattention and hyperactivity/impulsivity should be addressed to provide appropriate treatment to children and adolescents with ADHD who exhibit aggressive behavior.
\end{abstract}

Key Words: Attention-deficit/hyperactivity disorder; Attention; Child; Adolescent; Aggression; Working memory.

Received: May 20, 2020 / Revision: June 23, 2020 / Accepted: July 2, 2020

Address for correspondence: Yeon Jung Lee, Department of Psychiatry, Seoul Hospital, College of Medicine, Soonchunhyang University, 59 Daesagwan-ro, Yongsan-gu, Seoul 04401, Korea

Tel: +82-2-709-9081, Fax: +82-2-792-9938, E-mail: leeyj1203@schmc.ac.kr

\section{INTRODUCTION}

According to the Diagnostic and Statistical Manual of Mental Disorders-5th Edition (DSM-5) of the American Psychiatric Association, attention-deficit/hyperactivity disorder (ADHD) is a common childhood psychiatric disorder [1]. The main symptoms of ADHD are inattention, hyperactivity, and impulsivity; the onset of ADHD occurs in childhood before the age of 12 and influences many functional aspects of life, such as home, school, emotional control, and social relationships [1]. It is important to help children with ADHD access appropriate treatments and aid them in social adaptation before their symptoms worsen. ADHD symptoms are known to persist from childhood into adulthood [2]; indeed,

This is an Open Access article distributed under the terms of the Creative Commons Attribution Non-Commercial License (https://creativecommons.org/licenses/by-nc/4.0) which permits unrestricted non-commercial use, distribution, and reproduction in any medium, provided the original work is properly cited. although adults do not always meet diagnostic criteria, the duration of ADHD symptoms in adulthood is reported to be about $30-70 \%[3,4]$.

Among the ADHD symptoms, inattention persists most often into adulthood [5]. ADHD-inattentive type (ADHD-I) is frequently seen in girls and has more comorbid internalizing disorders [5]. However, it is difficult for teachers and parents to perceive this characteristic because it is characterized by hypo-arousal, low activity, and passive social relationships [6]. Conversely, ADHD-combined type (ADHD-C) is characterized by distraction and sloppy work [7]. If these symptoms persist into adulthood, they are not only associated with low socioeconomic status, mental illness, and increased dysfunction [5] but also with low academic and work performance, lack of interpersonal skills, emotional problems, antisocial behavior, and adaptation difficulties [8].

Inattention is known to be associated with working mem- 
ory in various cognitive domains of ADHD children [9]. Children with ADHD are reported to have various cognitive impairments in various areas, including working memory, executive function, organization, processing speed, and intelligence [10]. Among these impairments, weakness in working memory has been attracting attention as an internal phenotype of ADHD [11]. Inattention has been reported as being more significant among children with low working memory by the parent report scale of ADHD symptoms [12]. Children with ADHD have been shown to have more inattention in phonological and visuospatial working memories than healthy control children $[10,13]$.

Aggressive behavior for children with ADHD, although not included in the diagnostic criteria, is highlighted as one of the secondary problems in children with ADHD [14]. For such children, aggressive behavior, defined as hostile, harmful, or destructive behavior [15], is reactive aggression associated with the prefrontal lobe [16]. In an environment that caused reactive aggression, a group of children with ADHD/ Disruptive Behavior Disorder showed lower activation in the prefrontal lobe than the healthy control group [17]. The prefrontal lobe is a region closely correlated with persistent attention as well as inhibition [18]. Children with ADHD showed higher aggressive behavior compared to the healthy control group in the aggressive behavior scale of Child Behavior Checklist (CBCL). As with other ADHD subtypes [i.e., ADHD-C and ADHD-Hyperactive/Impulsive type (ADHD-H)], ADHD-I children showed higher aggressive behavior scores than the healthy control group [19]. This neurological correlation predicts that aggressive behavior can be a behavioral problem in children with ADHD who suffer from inattention as their main symptom [17].

Previous studies have investigated the positive correlation between aggressive behavior and hyperactivity/impulsivity in children with ADHD [20]. However, peers, parents, and teachers often interpret interpersonal behavior due to hyperactivity/impulsivity and social immaturity of children with ADHD as aggressive behavior [21]. Another previous study reported that the aggressive behavior of children with ADHD is more dominant in ADHD-C and ADHD-I children than in ADHD-H children [19]. Therefore, this study focuses on inattention persisting more than other symptoms until adulthood [4], the close relationship between inattention and working memory [11], and the aggressive behavior that is more dominant in ADHD-I children than ADHD-H children [19]. Based on the existing research, we hypothesized the following: 1) a positive correlation exists between inattention and aggressive behavior; 2) working memory influences the relationship between inattention and aggressive behavior, serving as a moderating effect; 3 ) there is a level at which the positive influence of working memory manifests.

\section{METHODS}

\section{Subjects}

This study retrospectively reviewed the medical records of children and adolescents $(n=118)$ admitted to the university hospital in Seoul, South Korea, from March 2015 to September 2018. Among the subjects, 38 children (age 6-10) and 39 adolescents (age 11-16) were both in- and out-patients who visited the hospital due to inattention or hyperactivity/impulsivity. They completed a comprehensive psychological test, including the Korean Wechsler Intelligence Scale for Children-Fourth Edition (K-WISC-IV), the Korean Child Behavior Checklist (K-CBCL), and the Children's Depression Inventory (CDI). Five children and seven adolescents with intellectual disability (ID), two children and six adolescents who scored 22 points (mildly depressed status) or more in CDI were excluded. This study was approved by the Institutional Review Board at Soonchunhyang University Seoul Hospital (IRB 2018-09-011). Obtaining consent was not necessary for this study, owing to its retrospective nature.

\section{Measures}

\section{Wechsler Intelligence Scale for Children}

The Wechsler Intelligence Scale for Children-Fourth Edition (WISC-IV) is an intelligence test performed individually on children and adolescents. The K-WISC-IV evaluates the cognitive abilities of children and adolescents from age 6-16, and the main outcome is the Full-Scale IQ (FSIQ). Indices include the Working Memory Index (WMI), Processing Speed Index (PSI), Perceptual Reasoning Index (PRI), and Verbal Comprehension Index (VCI). The score ranges are 69 and below (extremely low), 70-79 (borderline), 80-89 (low average), 90-109 (average), 110-119 (high average), 120129 (superior) and 130 and over (very superior). A trained clinical psychologist performed the test following the instructions in the manual. This study used the average score of the four indices and FSIQ indicators standardized in Korea [22].

\section{Child Behavior Checklist}

The CBCL measured the emotional and behavioral problems of children and adolescents between the ages of 6 and 18 and was completed by a parent or the child's primary caregiver. It was developed by Achenbach and Edelbrock (1983), and the K-CBCL was standardized by Oh et al. [23]. It comprises 118 items evaluated on a three-point Likert scale, not at all true ( 0 points), sometimes or tends to be true (1 point), or frequently or very much true (2 points). The scales are di- 
vided into a Social Competence Scale and a Problem Behavior Scale. The Problem Behavior Scale has eight subscales (withdrawn, somatic complaints, anxious/depressed, social problems, thought problems, attention problems, delinquent behavior, and aggressive behavior) as well as internalization, externalization, and total behavior problems. In this study, data concerning only two of the eight subscales in the problem behavior scale-attention problems and aggressive behavior-were used in the analyses; "attention problems" was named "inattention." The higher the score on each scale, the more severe the symptoms.

\section{Statistical analyses}

According to the groups of children and adolescents, the homogeneity of each research variable was verified by using the Mann-Whitney test. Because VCI, PRI, WMI, and PSIthe sub-scales of K-WISC-IV-have interaction effects, we performed a partial correlation analysis to determine the relationship between inattention, aggressive behavior, and WMI after controlling for VCI, PRI, and PSI. The moderating effect of working memory on the relationship between inattention and aggressive behavior was tested using Haye's PROCESS Macro Model 1, based on the regression analysis. The statistical significance of working memory by level was tested using the Johnson-Neyman Technique, which specifically suggests a certain area where the moderating effect is significant.

The criterion for statistical significance in the Mann-Whitney test and partial correlation analysis was set at $\mathrm{p}<0.001$. The moderating effect of working memory was set following the range of confidence intervals, not including zero. All data were processed using the SPSS win 23.0 program (IBM Corp., Armonk, NY, USA).

\section{RESULTS}

\section{Demographic characteristics of the participants}

In the final analysis, the data from 57 participants (excluding participants who had ID or depression) were used. The demographic characteristics are shown in Table 1.

\section{Verification of homogeneity}

Table 2 details the difference and homogeneity of the two groups. The difference between the two groups according to age was significant $(Z=6.51, \mathrm{p}<0.001)$, with 31 for children $(8.55 \pm 1.31)$ and 26 for adolescents $(12.46 \pm 1.39)$. The FSIQ $(\mathrm{p}=0.591)$, VCI $(\mathrm{p}=0.917)$, PRI $(\mathrm{p}=0.516)$, WMI $(\mathrm{p}=0.872)$, and PSI $(\mathrm{p}=0.841)$ were all homogeneous even if there were some differences among children and adolescents.

Inattention $(\mathrm{p}=0.610)$ and aggressive behavior $(\mathrm{p}=0.500)$ were also homogeneous in children and adolescents.

\section{The relationship between working memory, inattention, and aggressive behavior}

The results of the correlation after controlling for VCI, PRI, and PSI (between VCI, PRI, WMI, and PSI, which are subindices of K-WISC-IV) to determine the relationships between WMI, inattention, and aggressive behavior are shown in Table 3. There was a positive correlation between inattention and aggressive behavior $(\mathrm{r}=0.58, \mathrm{p}<0.001)$. However,

Table 1. Demographic characteristics of the participants $(n=57)$

\begin{tabular}{lc}
\hline \multicolumn{1}{c}{ Variable } & $\mathrm{n}(\%)$ \\
\hline Sex & \\
Children & $19(61.3)$ \\
$\quad$ Male & $12(38.7)$ \\
$\quad$ Female & \\
Adolescents & $14(53.8)$ \\
$\quad$ Male & $12(46.2)$ \\
Female & $10.33 \pm 2.38$ \\
Age (mean \pm SD)
\end{tabular}

SD: standard deviation

Table 2. Verification of homogeneity by research variables of children and adolescents with ADHD $(n=57)$

\begin{tabular}{|c|c|c|c|c|c|}
\hline Variable & $n$ & Mean & SD & $z$ & $p$ \\
\hline \multicolumn{6}{|l|}{ K-WISC-IV } \\
\hline$F S I Q$ & & & & 0.54 & 0.591 \\
\hline Children & 31 & 92.00 & 16.93 & & \\
\hline Adolescents & 26 & 93.08 & 13.31 & & \\
\hline $\mathrm{VCl}$ & & & & 0.10 & 0.917 \\
\hline Children & 31 & 97.45 & 15.11 & & \\
\hline Adolescents & 26 & 96.54 & 13.85 & & \\
\hline PRI & & & & 0.65 & 0.516 \\
\hline Children & 31 & 97.13 & 18.91 & & \\
\hline Adolescents & 26 & 96.31 & 20.96 & & \\
\hline WMI & & & & 0.16 & 0.872 \\
\hline Children & 31 & 88.65 & 16.25 & & \\
\hline Adolescents & 26 & 90.23 & 16.94 & & \\
\hline PSI & & & & 0.20 & 0.841 \\
\hline Children & 31 & 89.00 & 22.19 & & \\
\hline Adolescents & 26 & 90.31 & 13.40 & & \\
\hline \multicolumn{6}{|l|}{$\mathrm{K}-\mathrm{CBCL}$} \\
\hline Inattention & & & & 0.51 & 0.610 \\
\hline Children & 31 & 58.26 & 7.88 & & \\
\hline Adolescents & 26 & 59.04 & 7.57 & & \\
\hline Aggressive behavior & & & & 0.67 & 0.500 \\
\hline Children & 31 & 57.03 & 6.78 & & \\
\hline Adolescents & 26 & 56.73 & 8.63 & & \\
\hline
\end{tabular}

K-WISC-IV: Korean Wechsler Intelligence Scale for Children (fourth edition), FSIQ: Full Scale Intelligence Quotient, VCl: Verbal Comprehension Index, PRI: Perceptual Reasoning Index, WMI: Working Memory Index, PSI: Processing Speed Index, K-CBCL: Korean Child Behavior Checklist, SD: standard deviation 
WMI did not have a positive correlation with inattention ( $\mathrm{r}=$ $-0.52, p=0.711$ ). Furthermore, the relationship between WMI and aggressive behavior was not statistically significant $(\mathrm{r}=$ $0.01, \mathrm{p}=0.978)$.

\section{The moderating effect of working memory}

The moderating effect of working memory on the relationship between inattention and aggressive behavior is shown in Table 4. Although inattention did not affect aggressive behavior $[\mathrm{b}=-0.88, \mathrm{p}=0.171(-2.16,0.39)]$, working memory was found to have a statistically significant negative effect on aggressive behavior $[b=-0.92, p=0.028(-1.73,-0.10)]$. Concerning the moderating effect, it was found that inattention and working memory interact to have a statistically significant positive effect on aggressive behavior $[b=0.02, p=0.024(0.01$, $0.03)]$. VCI $[\mathrm{b}=0.10, \mathrm{p}=0.168(-0.04,0.24)]$, PRI $[\mathrm{b}=-0.07, \mathrm{p}=$ $0.153(-0.17,0.03)]$, and PSI $[\mathrm{b}=-0.03, \mathrm{p}=0.583(-0.12,0.07)]$, which are other sub-indices of K-WISC-IV, were found to not affect aggressive behavior (Table 4). The WMI, which had moderating effects based on its interaction with inattention,

Table 3. Correlation between working memory, inattention, and aggressive behavior $(n=57)$

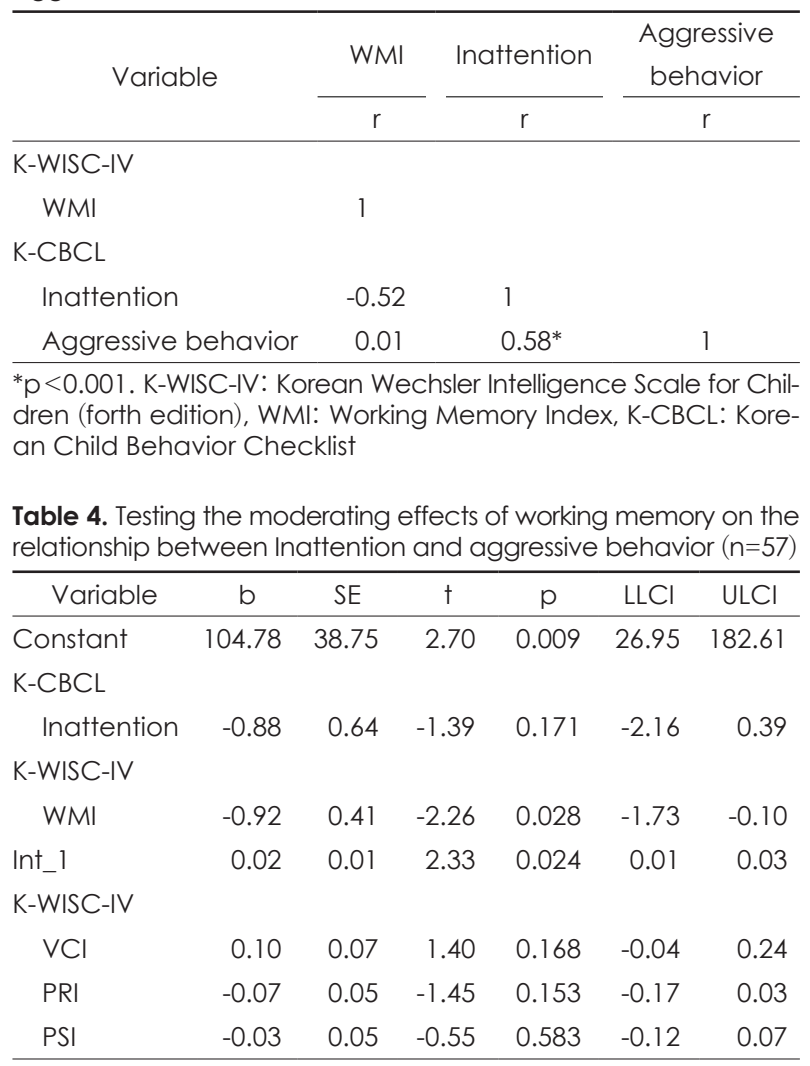

Int_l: the moderating effect of working memory interacted with inattention to positively affect aggressive behavior, SE: standard error, LLCl: low limit confidence interval, ULCl: upper limit confidence interval, K-WISC-IV: Korean Wechsler Intelligence Scale for Children (fourth edition), WMl: Working Memory Index, K-CB$\mathrm{CL}$ : Korean Child Behavior Checklist was found to be significant $[\mathrm{b}=0.02, \mathrm{p}=0.024(0.01,0.03)]$. Furthermore, the moderating effect of working memory manifested when the WMI score on the K-WISC-IV was greater than or equal to 73.5 points and had a significant effect on aggressive behavior (Fig. 1).

\section{DISCUSSION}

This study aimed to understand the effect of working memory on the relationship between inattention and aggressive behavior in children and adolescents with ADHD. Some significant results were obtained from the analysis. First, among the sub-indices of K-WISC-IV in children with ADHD, the mean levels of WMI $(\mathrm{M}=88.65, \mathrm{SD}=16.25)$ and PSI $(\mathrm{M}=89.00$, $\mathrm{SD}=22.19)$ were low average, which was lower than the mean levels of VCI $(M=97.45, S D=15.11)$ and PRI $(M=97.13, S D=$ 18.91). Second, inattention in children and adolescents with ADHD was found to be positively correlated with aggressive behavior. Third, the moderating effect of working memory interacted with inattention to positively affect aggressive behavior. Fourth, the positive moderating effect of working memory was found to manifest when the WMI score was greater than or equal to 73.5 points.

First, among the sub-indices of K-WISC-IV in children with ADHD, the mean levels of WMI and PSI were low average, which was lower than the mean levels of VCI and PRI. The correlation between inattention of children with ADHD and WMI/PSI was reported to be low average in various studies similar to the results of this study. The low level of two subindices were observed in ADHD-I children [24]. However, in another study that distinguished the sub-indices of WISCIV as predictors of inattention severity and treatment results in children with ADHD-I, only PSI was reported as a predictive index [25]. In this study, we confirmed the effect of working memory and controlled other cognitive functions that could interact with it (i.e., PSI, VCI, and PRI). However, the sample size was small, and this is a single-institution study; future studies are necessary with larger samples.

Second, inattention in children and adolescents with ADHD was positively correlated with aggressive behavior. An existing study on aggressive behavior in children with ADHD has been conducted concerning inattention and hyperactivityimpulsivity [20]. To determine the effect of major symptoms of ADHD on adult criminal involvement, the authors collected childhood data and adult statuses. As a result, hyperactivity-impulsivity was reported to be relevant, but not inattention [20]. However, aggressive behavior in children and adolescents with ADHD is not only a problem that can be seen in ADHD-HI but a behavioral problem of all children and adolescents with ADHD. Previous studies have report- 


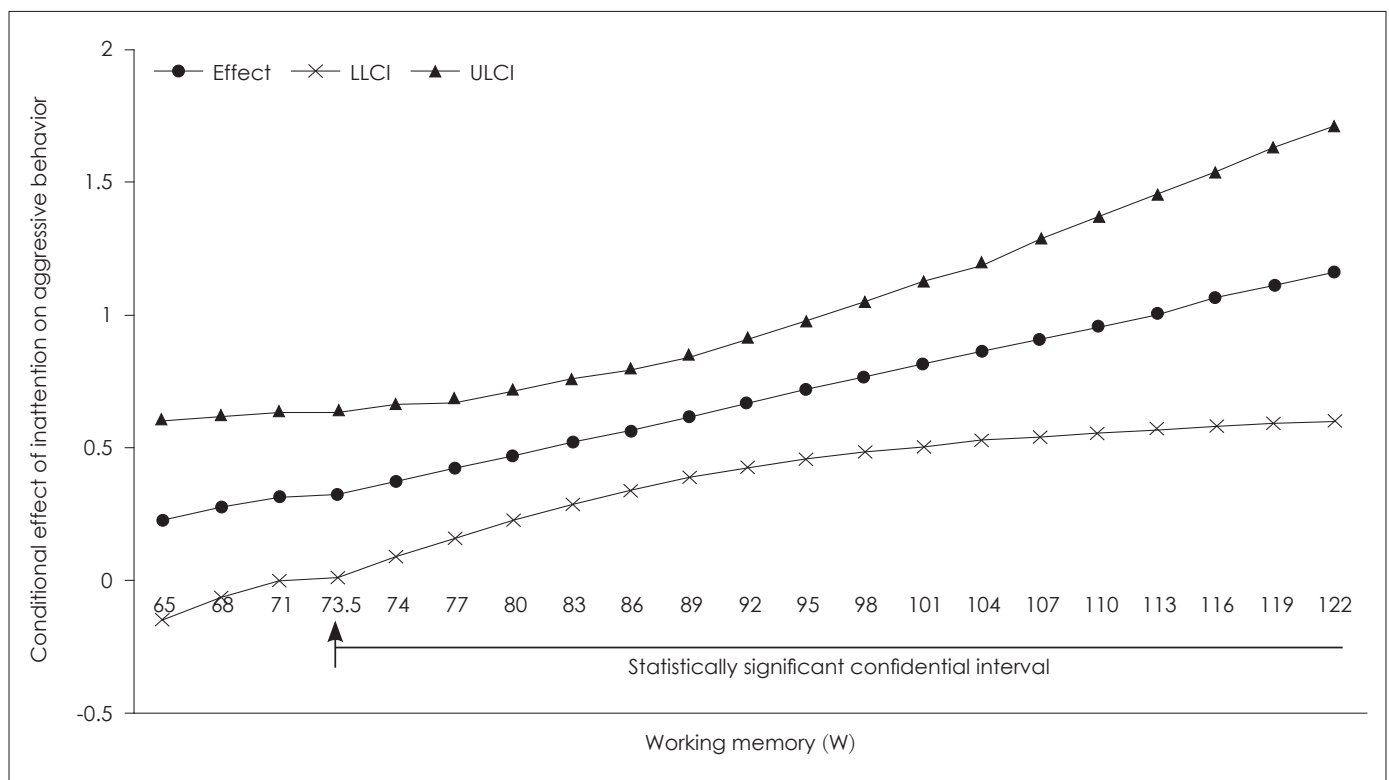

Fig. 1. The conditional effect of inattention $(X)$ on aggressive behavior $(\theta x \rightarrow y)$ as a function of working memory (W). LLCl: low limit confidence interval, ULCI: upper limit confidence interval.

ed that aggressive behavior is more prominent in ADHD-C and ADHD-I children than ADHD-HI children [19]. In another study, when the normal group and subtypes of ADHD were compared, girls with ADHD-I showed higher aggressive behavior than girls with other subtypes of ADHD [26]. The results of our study, which showed a correlation between inattention and aggressive behavior in children and adolescents with ADHD as in previous studies [19,26], demonstrated that besides hyperactivity/impulsivity, inattention was also important in the evaluation of children and adolescents with ADHD.

Third, the moderating effect of working memory and its interaction with inattention positively affect aggressive behavior. Previous studies focused on the direct correlation between working memory and aggressive behavior [27]. However, this study may have produced different results because it tried to find the indirect moderating effect on the relationship between inattention and aggressive behavior. Additionally, when using the same variable in the analysis, there may not be a significant interaction in the moderating effect, even if there is a significant correlation [28]. Previous studies did not have any condition to control for other cognitive functions or interact with attention problems. Because the cognitive functions of humans have an interactive effect, it is difficult to ignore the effects of other cognitive functions [29]. Indeed, one previous study reported that damage to the working memory of children with ADHD can affect their processing speed and that slower processing speed played a role in developing reading disorders [30]. Therefore, controlling for other cognitive functions and analyzing correlations and moderating effects can provide important information about the positive effects of how working memory interacts with inattention to produce moderating effects on aggression.

Fourth, the positive moderating effect of working memory was found to manifest when the WMI score was greater than or equal to 73.5 points. Many studies have been conducted on the low levels of cognitive function in children with ADHD [24]. Most of these studies focused on children with ADHD having weakness or low levels of WMI [11,24]. However, our results showed that if children or adolescents who have been diagnosed with ADHD or have inattention, have a level of WMI that is 73.5 points (borderline) or higher, inattention manifests clinically aggressive behavior. This finding implies that the focus should not only be on the low WMI levels of ADHD children and adolescents but also the fact that working memory affects aggressive behavior by interacting with inattention. One must be aware of the severity of the children and adolescents' inattention when treating their aggressive behavior.

Despite these significant findings, this study has several limitations. First, the sample size was relatively small, and the study was conducted in children and adolescents treated at a single institution. Therefore, there may be limitations concerning the generalizability of the results to all children and adolescents with ADHD. It is necessary to research with larger samples from multi-institutions in the future. Second, because this is a retrospective study and we did not exclude the effects of medication, care must be taken when interpreting the results. At the time of this study, 23 of the children were taking medication (methylphenidate: seven subjects; 
atomoxetine: five subjects; aripiprazole: five subjects; escitalopram: six subjects), and some subjects were prescribed more than one medication. Therefore, future studies need to be conducted by targeting children and adolescents not on medication or by proactively controlling the medication intake of the subjects. Third, we did not ascertain the existence of comorbid diseases other than depression. Although the coexistence of depression in ADHD was excluded using CDI, further studies are necessary to supplement this and evaluate other comorbid diseases. Fourth, we did not discriminate among the main sub-symptoms of children and adolescents with ADHD. In $\mathrm{ADHD}$, there are cognitive and behavioral differences between the main sub-symptoms. In the future, selecting only children and adolescents with inattention will help researchers examine the effect of inattention more thoroughly.

\section{CONCLUSION}

This study found that aggressive behavior in children and adolescents diagnosed with ADHD had a positive correlation with inattention. In addition, working memory had a moderating effect that interacted with inattention to have a positive effect on aggressive behavior. Therefore, inattention and working memory should be addressed when treating ADHD children and adolescents with aggressive behavior. Furthermore, it is necessary to confirm the related factors that lead to aggressive behavior and to identify aspects of aggressive behavior in children and adolescents with ADHD symptoms.

\section{Acknowledgments}

This work was supported by the Korean government (MSIT; Ministry of Science and ICT) [grant number 2017R1C1B5074462] and the Soonchunhyang University Research Fund.

\section{Conflicts of Interest}

The authors have no potential conflicts of interest to disclose.

\section{Author Contributions}

Conceptualization: Mi Young Jeong, Yeon Jung Lee. Data curation: Mi Young Jeong, Seo Young Park. Formal analysis: Jung Ho Kim. Funding acquisition: Yeon Jung Lee. Investigation: all authors. Visualization: Jung Ho Kim. Validation: Yeon Jung Lee. Writing_original draft: Mi Young Jeong. Writing-review \& editing: Yeon Jung Lee, Jung Ho Kim.

\section{ORCID iDs}

Mi Young Jeong https://orcid.org/0000-0002-2409-8060

Yeon Jung Lee https://orcid.org/0000-0001-8953-5893

Jung Ho Kim https://orcid.org/0000-0003-2763-7186

Seo Young Park https://orcid.org/0000-0002-5033-8689

\section{REFERENCES}

1) American Psychiatric Association. Diagnostic and statistical manual of mental disorders: DSM-5. 5th ed. Arlington, VA: American Psychaitric Association;2013.
2) Mannuzza S, Klein RG, Bessler A, Malloy P, LaPadula M. Adult outcome of hyperactive boys: educational achievement, occupational rank, and psychiatric status. Arch Gen Psychiatry 1993;50: 565-576.

3) Mannuzza S, Klein RG, Bonagura N, Malloy P, Giampino TL, Addalli KA. Hyperactive boys almost grown up: V. replication of psychiatric status. Arch Gen Psychiatry 1991;48:77-83.

4) Tuithof M, Ten Have M, van Dorsselaer S, de Graaf R. [Prevalence, persistency and consequences of ADHD in the Dutch adult population]. Tijdschr Psychiatr 2014;56:10-19.

5) Weiss M, Worling D, Wasdell M. A chart review study of the inattentive and combined types of ADHD. J Atten Disord 2003;7:1-9.

6) Barkley RA, DuPaul GJ, McMurray MB. Comprehensive evaluation of attention deficit disorder with and without hyperactivity as defined by research criteria. J Consult Clin Psychol 1990;58:775-789.

7) Hartman CA, Willcutt EG, Rhee SH, Pennington BF. The relation between sluggish cognitive tempo and DSM-IV ADHD. J Abnorm Child Psychol 2004;32:491-503.

8) Barkley RA, Fischer M, Smallish L, Fletcher K. Young adult outcome of hyperactive children: adaptive functioning in major life activities. J Am Acad Child Adolesc Psychiatry 2006;45:192-202.

9) Kofler MJ, Rapport MD, Bolden J, Sarver DE, Raiker JS. ADHD and working memory: the impact of central executive deficits and exceeding storage/rehearsal capacity on observed inattentive behavior. J Abnorm Child Psychol 2010;38:149-161.

10) Barkley RA. Behavioral inhibition, sustained attention, and executive functions: constructing a unifying theory of ADHD. Psychol Bull 1997;121:65-94.

11) Willcutt EG, Doyle AE, Nigg JT, Faraone SV, Pennington BF. Validity of the executive function theory of attention-deficit/hyperactivity disorder: a meta-analytic review. Biol Psychiatry 2005;57: 1336-1346.

12) Lui $\mathbf{M}$, Tannock R. Working memory and inattentive behaviour in a community sample of children. Behav Brain Funct 2007;3:12.

13) Kasper LJ, Alderson RM, Hudec KL. Moderators of working memory deficits in children with attention-deficit/hyperactivity disorder (ADHD): a meta-analytic review. Clin Psychol Rev 2012;32:605-617.

14) Siever LJ. Neurobiology of aggression and violence. Am J Psychiatry 2008;165:429-442.

15) Coccaro EF, Kavoussi RJ. Fluoxetine and impulsive aggressive behavior in personality-disordered subjects. Arch Gen Psychiatry 1997; 54:1081-1088

16) Yeo KE, Lee JJ, Lee MH. The effect of ADHD children's inadaptability act towards self-expression art activities. Journal of special education: theory and practice 2006;7:331-349.

17) Bubenzer-Busch S, Herpertz-Dahlmann B, Kuzmanovic B, Gaber TJ, Helmbold K, Ullisch MG, et al. Neural correlates of reactive aggression in children with attention-deficit/hyperactivity disorder and comorbid disruptive behaviour disorders. Acta Psychiatr Scand 2016;133:310-323.

18) Knight RT, Grabowecky MF, Scabini D. Role of human prefrontal cortex in attention control. Adv Neurol 1995;66:21-36.

19) Connor DF, Chartier KG, Preen EC, Kaplan RF. Impulsive aggression in attention-deficit/hyperactivity disorder: symptom severity, co-morbidity, and attention-deficit/hyperactivity disorder subtype. J Child Adolesc Psychopharmacol 2010;20:119-126.

20) Babinski LM, Hartsough CS, Lambert NM. Childhood conduct problems, hyperactivity-impulsivity, and inattention as predictors of adult criminal activity. J Child Psychol Psychiatry 1999;40:347355.

21) Pope AW, Bierman KL, Mumma GH. Relations between hyperactive and aggressive behavior and peer relations at three elementary grade levels. J Abnorm Child Psychol 1989;17:253-267.

22) Kwak KJ, Oh SW, Kim CT. Korean-Wechsler Intelligence Scale for Children. 4th ed. Seoul: Hakjisa;2011. 
23) Oh KJ, Lee HL, Hong KE, Ha EH. Korean version of child behavior checklist (K-CBCL). Seoul: ChungAng Aptitude Publishing;1997.

24) Mulder H, Pitchford NJ, Marlow N. Inattentive behaviour is associated with poor working memory and slow processing speed in very pre-term children in middle childhood. Br J Educ Psychol 2011;81:147-160.

25) Adalio CJ, Owens EB, McBurnett K, Hinshaw SP, Pfiffner LJ. Processing speed predicts behavioral treatment outcomes in children with attention-deficit/hyperactivity disorder predominantly inattentive type. J Abnorm Child Psychol 2018;46:701-711.

26) Zalecki CA, Hinshaw SP. Overt and relational aggression in girls with attention deficit hyperactivity disorder. J Clin Child Adolesc Psychol 2004;33:125-137.

27) Ziermans T, Dumontheil I, Roggeman C, Peyrard-Janvid M, Mats- son $\mathrm{H}$, Kere J, et al. Working memory brain activity and capacity link MAOA polymorphism to aggressive behavior during development. Transl Psychiatry 2012;2:e85.

28) Lin QL, Kim HK, Ann JS. Relationship between depression and quality of life in elderly women living alone: the moderating and mediating effects of social support and social activity. Journal of the Korea Gerontological Society 2011;31:33-47.

29) Fry AF, Hale S. Relationships among processing speed, working memory, and fluid intelligence in children. Biol Psychol 2000;54: $1-34$.

30) Jacobson LA, Ryan M, Martin RB, Ewen J, Mostofsky SH, Denckla $\mathrm{MB}$, et al. Working memory influences processing speed and reading fluency in ADHD. Child Neuropsychol 2011;17:209-224. 